\title{
CHARACTERISATION OF MUNICIPAL SEWAGE SLUDGE AS A SOIL IMPROVER AND A FERTILIZER PRODUCT
}

\author{
CHARAKTERYSTYKA OSADÓW ŚCIEKOWYCH \\ JAKO POLEPSZACZY GLEBY I PRODUKTÓW NAWOZOWYCH
}

\begin{abstract}
In this study, we have determined the main important physical and chemical properties of municipal sewage sludge and compared them to the requirements of the Finnish Fertilizer Product Act and Fertilizer Product Decree in order to assess the potential utilization of this by-product as a fertilizer. Except for $\mathrm{Hg}(1.4 \mathrm{mg} / \mathrm{kg} \mathrm{d} . \mathrm{m}$.), the total concentrations of $\mathrm{Cd}, \mathrm{Cu}, \mathrm{Ni}, \mathrm{Pb}, \mathrm{Zn}, \mathrm{Cr}$ and $\mathrm{As}$ in our sewage sludge were lower that the Finnish maximum permissible heavy metal concentrations for sewage sludge used as a fertilizer products. However, the sewage sludge may be utilized as a soil improver, a growing media or as a fertilizer product in landfill sites (e.g. surface structures) or in other closed industrial areas, because the above mentioned Finnish limit values are not applied at these sites. If the sewage sludge is to be utilized in these kinds of areas, an environmental permit may be needed. According to BCR-extraction, the lowest release potential (solubility) from the sample matrix was observed for sulphur (58.4\%) and the highest for Cd (100\%).
\end{abstract}

Keywords: BCR extraction, fertilizer, sewage sludge, wastewater treatment, waste

\section{Introduction}

Municipal sewage sludge is created for a good reason - it is the by-product of processes that clean our raw sewage before the cleaned effluent is discharged into receiving water bodies, e.g. seas, streams and estuaries. Municipal sewage contains not only human faeces waste but also products and contaminants from homes, industries, businesses, storm water, landfill leachate (in some locales) and contaminants leached from pipes [1]. Sewage sludge as an end-product of wastewater treatment processes reflects the composition of the raw wastewater and therefore anthropogenic activities in the treatment plant's sewerage system catchment. Depending of the type of municipal wastewater treatment plant (WWTP) and process installation, sludge may be generated during the primary (physical and/or chemical), the secondary (biological) and tertiary (additional to secondary, often

\footnotetext{
${ }^{1}$ Department of Environmental Protection, City of Kemi, Valtakatu 26, FI-94100 Kemi, Finland, phone +35816259673

${ }^{2}$ Environmental and Chemical Engineering Research Unit, Faculty of Technology, University of Oulu, FI-90014 Oulu, Finland

${ }^{3}$ Clean Technology Research Group, Department of Bioproducts and Biosystems, School of Chemical Technology, Aalto University, Espoo 00076 Aalto, Finland, phone +35840540107

"Corresponding author: risto.poykio@kemi.fi
} 
nutrient removal) treatment stages [2]. Due to the physical and chemical processes involved in the treatment, the sludge tends to concentrate trace metals, many of which are heavy metals, and poorly biodegradable trace organic compounds as well as partially pathogenic organisms (viruses, bacteria) present in the wastewater. Sludge is, however rich in nutrients such as nitrogen $(\mathrm{N})$ and phosphorous $(\mathrm{P})$ and contains valuable organic matter that is potentially useful for amelioration of soils that are depleted or subject to erosion. The organic matter and nutrients are two main elements that make the spreading of this kind of waste on land suitable as a fertilizer or as an organic soil improver, usually after hygienic treatment and or composting [3]. Furthermore, utilization of sewage sludge as a fertilizer may replace or at least reduce the use of mineral fertilizer in agronomic plant production [4].

According to the waste hierarchy of the European Union (EU), minimization and re-use of municipal sewage sludge are the most desirable options in order to recycle nutrients rather than incinerating it or sending it to landfill. Therefore, in the EU there is an increasing emphasis on the reuse of sewage sludge as a "product" for example as a fertilizer [5]. However, the re-use of municipal sewage sludge as a fertilizer has been debated in EU countries in recent decades, mainly due to concern over the bioaccumulation of heavy metal in the food chain [6]. Therefore, the regular analysis of sewage sludge composition is a key factor for quality assessment to insure the safe utilization of this residue. Prior to any such application, the determination of both the total heavy metal concentrations in sludge and their leaching (extraction) profiles is important to know [7]. The knowledge of total heavy metal concentrations in sludge is needed to insure, that national limit values are not exceeded if the sludge is used to agriculture. Although total metal concentrations in sludge usually obtained after microwave digestion in strong mineral acid solution is useful as an overall pollution indicator, they do not provide information on the metal-binding characteristics of heavy metals in sludge for estimating their ecological and biological effects [8]. If a sewage sludge is utilized it is possible that heavy metals contained in this residue could be released. The mobility of trace metals, their bioavailability and related eco-toxicity to plants depend strongly on their specific chemical forms or ways of binding. Extraction methods provide useful information about the bioavailability and potential mobility as well the eco-toxicity and environmental impacts of heavy metals in sewage sludge [9].

One of the most utilised extraction methods in assessing the metal-binding characteristics of heavy metals in waste materials is the three-step extraction procedure of the Standards, Measuring and Testing Programme of the Commission of the European Communities, which is a successor of Community Bureau of Reference (BCR) programme of the European Union [10]. In this procedure, the extraction is based upon acetic acid extraction (step 1: exchangeable and acid-soluble fraction), hydroxylamine hydrochloride extraction (step 2: reducible fraction) and hydrogen peroxide digestion following ammonium acetate extraction (step 3: oxidizable fraction). In the literature, this extraction is commonly known as the BCR sequential extraction [11].

The aim of this study was: (1) to determine the main important chemical and physical properties of a sewage sludge originating from a municipal wastewater treatment plant located in Finland, (2) to evaluate whether the municipal sewage sludge fulfils the requirement of the Finnish Fertilizer Product Act and Fertilizer Product Decree for fertilizer products, (3) to evaluate the release potential of heavy metals from the sludge using the 
three-step BCR-sequential extraction procedure, which are needed if the environmental permit is required for the utilization of this by-product.

\section{Materials and methods}

\section{Sampling}

The sewage sludge investigated in this study was obtained from a municipal wastewater treatment plant (WWTP) located in Finland. The WWTP began operation at the beginning of 1980 and its technical performance has improved continuously over the years. It is designed to treat the wastewaters from 34,000 inhabitants, treating about 3.1 million cubic metre $\left(\mathrm{m}^{3}\right)$ wastewaters annually, which correspondingly results to the production of about $2500 \mathrm{Mg}$ of sewage sludge. The treatment process of the WWTP is a combination of biological-chemical and simultaneous precipitation. Briefly, the main process units in the WWTP are: (1) a mechanical treatment unit, (2) a biological and chemical treatment unit and (iii) a sludge treatment unit. In the mechanical treatment unit, big items (e.g. stones, sticks, branches, plastics, nappies, rags, sanitary items, etc.) and smaller items (e.g. floating objects, sand, etc.) as well as the oil and grease that would clog and hinder subsequent treatment steps are taken out. In this unit undertakes the primary removal of the most coarse settleable organic and inorganic solids by sedimentation. In the chemical and biological treatment unit, the dissolved phosphorous $(\mathrm{P})$ in sewage is precipitated with the use of ferric sulphate $\left[\mathrm{Fe}_{2}\left(\mathrm{SO}_{4}\right)_{3}\right]$ and the reduction of other nutrients $(\mathrm{N}, \mathrm{P})$ occurs in the activated sludge process using micro-organisms (to degrade the biodegradable organics) and aeration (oxygen for respiration). In the sludge treatment unit, the sewage (slurry) is thicken and dried using a centrifuge before the sludge is removed from the plant. The effluent loads from the WWTP in 2017 were as follows: effluent volume $8520 \mathrm{~m}^{3} / \mathrm{d}$, a seven-day biological oxygen demand using allylthiourea as oxidizing agent $\left(\mathrm{BOD}_{7}(\mathrm{ATU})\right) 40 \mathrm{~kg} / \mathrm{d}$, chemical oxygen demand using potassium dichromate as oxidizing agent $\left(\mathrm{COD}_{\mathrm{cr}}\right) 259 \mathrm{~kg} / \mathrm{d}, T P$ (total phosphorus) $2.7 \mathrm{~kg} / \mathrm{d}, T N$ (total nitrogen) $284 \mathrm{~kg} / \mathrm{d}, \mathrm{NH}_{4}-\mathrm{N} 243 \mathrm{~kg} / \mathrm{d}$ and total suspended solids (TSS) $56 \mathrm{~kg} / \mathrm{d}$. The absorbable organic halogens (AOX) load from the WWTP is not known, because AOX monitoring is not required by the environmental permit.

The sludge sampling period represented normal process operating conditions for the wastewater treatment plant. The sewage sludge investigated in this study was sampled from the centrifuge, which is used for the dewatering of sludge. After sampling, the sludge sample was stored in a polyethylene bag in a refrigerator $\left(+4{ }^{\circ} \mathrm{C}\right)$. Samples should be analysed as soon as possible after sampling. However, if this is not done, according to EPA [12], they should be chemically/physically preserved as soon as possible after sampling to avoid or minimise biological, chemical or physical changes that can occur between the time of collection and analysis. For the above-mentioned reasons we decided to follow the procedure of Stylianou et al. [13] and to store the sample in a refrigerator $\left(+4{ }^{\circ} \mathrm{C}\right)$ until analysis.

\section{Determination of the mineralogical composition, physical and chemical properties of the sludge}

The mineralogical composition of the sewage sludge was determined with a Siemens D 5000 diffractometer (Siemens AG, Karlsruhe, Germany) using $\mathrm{CuK \alpha}$ radiation. The scan was run from 2 to $80^{\circ}$ (2-Theta scale), with increments of $0.02^{\circ}$ and a counting time of 
1.0 second per step. The operating conditions were $40 \mathrm{kV}$ and $40 \mathrm{~mA}$. Peak identification was carried out with the DIFFRACplus BASIC Evaluation Package PDFMaint 12 (Bruker axs, Germany) and the software package ICDD PDF-2 Release 2006 (Pennsylvania, USA).

Determination of $\mathrm{pH}$ in the sewage sludge was carried out according to European standard SFS-EN 13037 at a solid-to-liquid (ultrapure $\mathrm{H}_{2} \mathrm{O}$ ) ratio of 1:5. Determination of the dry matter content (DMC) of the sludge was carried out according to European standard SFS-EN 12880, in which a sample is dried overnight to a constant mass in an oven at $105^{\circ} \mathrm{C}$. The total organic matter content (TOC) of the sludge, which also indicates the total organic carbon (C) content [14], was carried out according to European standard SFS-EN 13137. The loss-on-ignition (LOI) of the sludge was carried out according to European standard SFS-EN 12879. Details of the analytical methods of these standards can be found in our previous publication [15].

\section{Determination of the total nutrient and heavy metal concentrations in the sludge}

To determine the total nutrient $(\mathrm{P}, \mathrm{Ca}, \mathrm{Na}, \mathrm{K}, \mathrm{Mg}$ and $\mathrm{Zn})$ and total heavy metal concentrations in the sewage sludge, the dried sample was digested with a mixture of $\mathrm{HCl}$ $\left(3 \mathrm{~cm}^{3}\right)$ and $\mathrm{HNO}_{3}\left(9 \mathrm{~cm}^{3}\right)$ in a CEM Mars 5 microprocessor-controlled microwave oven with a CEM HP 500 Teflon vessels (CEM Corp., Matthews, USA) using USEPA method 3051A [16]. This digestion method is accepted in Finnish legislation for the total element digestion [17]. Determination of the total nitrogen concentration in the sludge was carried out according to the European standard SFS-EN 13654-1 by the Kjeldahl method using a Foss-Tecator Kjeltee 2300 Analyzer (Hoganas, Sweden) equipped with a Foss-Tecator 2020 Digestor (Hoganas, Sweden) [15].

The cooled solution was transferred to a $100 \mathrm{~cm}^{3}$ volumetric flask and the solution diluted to volume with ultrapure water. The ultrapure water was generated by an Elgastat Prima reverse osmosis and Elgastat Maxima ion exchange water purification system (Elga Ltd; Bucks, England). All reagents and acids were super pure or pro analysis quality. Apart from $\mathrm{Hg}$, the total nutrient ( $\mathrm{P}, \mathrm{Ca}, \mathrm{Na}, \mathrm{K}, \mathrm{Mg}$ and $\mathrm{Zn}$ ) and heavy metal concentrations in sludge were determined with ICP-OES (Thermo Fisher Scientific iCAP6500 Duo, UK). The concentration of $\mathrm{Hg}$ in the sludge was determined with a Perkin Elmer Aanalyst 700 cold-vapour AAS equipped with a Perkin Elmer FIAS 400 and AS 90 plus auto-sampler [15].

\section{Three-step BCR sequential extraction procedure for heavy metals in the sludge}

The three-step sequential extraction scheme for the fractionation of heavy metals in sewage sludge as well as the quality control results of the BCR extraction can be found in our previous paper [15]. Briefly, the sequential extraction was carried out as follows: (1) acetic acid $\left(\mathrm{CH}_{3} \mathrm{COOH} ; 0.1 \mathrm{~mol} / \mathrm{dm}^{3} ; \mathrm{pH}=3.0\right)$ extraction to recover the heavy metals in the sludge into the exchangeable fraction, (2) hydroxylamine hydrochloride $\left(\mathrm{NH}_{2} \mathrm{OH}-\mathrm{HCl}\right.$ in nitric acid medium, $\left.0.1 \mathrm{~mol} / \mathrm{dm}^{3} ; \mathrm{pH}=2.0\right)$ extraction to recover the heavy metals in the sludge into the easily reduced fraction, and (3) hydrogen peroxide digestion $\left(\mathrm{H}_{2} \mathrm{O}_{2} ; 30 \%\right)$ followed by ammonium acetate $\left(\mathrm{CH}_{3} \mathrm{COONH}_{4} ; 1.0 \mathrm{~mol} / \mathrm{dm}^{3} ; \mathrm{pH}=2.0\right)$ extraction to recover the heavy metals in the sludge into the oxidizable fraction. In the literature, the widely used abbreviation for the exchangeable fraction is BCR1, correspondingly BCR 2 for the easily reduced fraction and BCR3 for the oxidizable fraction [18]. Therefore we have used the above mentioned abbreviations in this paper, too. 
In order to avoid possible chemical and/or microbiological changes in the sludge, the extraction was carried out using the sample as such, instead of a dried sample, since Karczmarek and Studzinski [19] have observed that drying of sludge before sequential extraction change the form in which the elements occur in the sludge and cause immobilization of the elements. After each extraction step, the extracts were separated from the solid residue by filtration through a $0.45 \mu \mathrm{m}$ membrane filter $(47 \mathrm{~mm}$ diameter; Schleicher \& Schuell, Dassel, Germany). In order to avoid losses between the extraction stages, the filters and adhering residue particles from the previous extraction stage were also included in the next stage. After the addition of $200 \mathrm{~mm}$ of $65 \% \mathrm{HNO}_{3}$ to the supernatant phase, it was stored in a refrigerator $\left(+4{ }^{\circ} \mathrm{C}\right)$ until the extraction test was performed and trace element concentrations were determined. The element concentrations in the extracts (extraction stages 1-3) were determined with a Thermo Fisher Scientific iCAP6500 Duo (United Kingdom) inductively coupled plasma optical emission spectrometer (ICP-OES).

\section{Results and discussion}

\section{Mineralogical composition, physical and chemical properties of the sludge}

According to the XRD spectra, only quartz $\left(\mathrm{SiO}_{2} ; 38.4 \%\right)$, albite $\left(\mathrm{NaAlSi}_{3} \mathrm{O}_{8} ; 36.9 \%\right)$ and magnesium phosphate hydrate $\left(\left(\mathrm{Mg}_{3}(\mathrm{PO} 4)_{2}\left(\mathrm{H}_{2} \mathrm{O}\right)_{8}\right) ; 24.7 \%\right)$ could be identified in the sewage sludge investigated in this study. Our XRD spectra are consistent with the findings of Dabrowska [20], who observed also quartz in the municipal sewage sludge. Our XRD-spectra agree also with the findings of Wang and Xue [21], who detected quartz and albite in municipal sewage sludge. In this context it is worth noting that an XRD spectrometer is unable to identify the amorphous (glass) phase (non-crystallised matter), and its detection limit is normally $1-2 \%(\mathrm{w} / \mathrm{w})$. This is why crystalline compounds containing all the heavy metals in Table 2 were not identified by XRD, despite the fact that the concentrations of these elements could be quantitatively measured by ICP-OES.

The main important physical and chemical properties of the investigated sewage sludge are presented in Table 1, which also presents the properties of sewage sludges collected from selected wastewater treatments plants in 15 European countries (including Finland) and in Finnish humus [22-24].

Table 1

The main important physical and chemical properties of the sewage sludge investigated in this study as well as in other European (EU) sludges [22-24] and in Finnish humus

\begin{tabular}{|c|c|c|c|}
\hline Property/nutrient & This study & EU sludge & Finnish humus \\
\hline $\mathrm{pH}[-]$ & 6.1 & & \\
\hline DMC [\%] & 23.6 & $15-31$ & \\
\hline LOI [\%] & 74.3 & & \\
\hline TOC [g/kg d.m.] & 303 & & \\
\hline $\mathrm{N} \mathrm{[mg/kg} \mathrm{d.m.]}$ & 39800 & $10000-56000$ & 2610 \\
\hline $\mathrm{P}[\mathrm{mg} / \mathrm{kg} \mathrm{d.m.]}$ & 20600 & & 50 \\
\hline $\mathrm{Ca} \mathrm{[mg/kg} \mathrm{d.m.]}$ & 17500 & & 927 \\
\hline $\mathrm{Na} \mathrm{[mg/kg} \mathrm{d.m.]}$ & 320 & $1000-26000$ & 531 \\
\hline $\mathrm{K}[\mathrm{mg} / \mathrm{kg} \mathrm{d.m.]}$ & 1810 & $100-22400$ & 40.5 \\
\hline $\mathrm{Mg}[\mathrm{mg} / \mathrm{kg} \mathrm{d.m}]$ & 2510 & $200-1200$ & \\
\hline $\mathrm{Zn} \mathrm{[mg/kg} \mathrm{d.m.]}$ & 350 & & \\
\hline
\end{tabular}


Our sewage sludge was slightly acidic $(\mathrm{pH}=6.1)$. The importance of the $\mathrm{pH}$ value of sludge emerges from the fact that the solubility of heavy metals in a sludge sample is $\mathrm{pH}$-dependent, since the $\mathrm{pH}$ controls the bioavailability of metals and particularly those metals that exist largely in the labile form [25]. The dry matter content (DMC) of the sludge was relatively low (23.6\%), which means that its water content was high (76.4\%) and this agrees with the dry matter content between 15 and $31 \%$ observed in other Finnish sewage sludges [24].

The high water content $(76.4 \%)$ is our sewage sludge is reasonable in the light of the fact that the sludge in the waste water treatment plant from where it was sampled is dewatered mechanically using a centrifuge. Water in sludge can be in the following forms, namely: (1) free water (bulk water) - water not associated with solid particles including void water not associated with capillary forces, (2) intestinal water - water trapped in crevices and interstitial spaces of flocs and microbes, (3) vicinal water - water held to particle surfaces by adsorption and adhesion, for instance by hydrogen bonding and (4) water of hydration - water chemically bound within the particle structure [26]. Although conventional mechanical sludge dewatering methods (centrifuge, filter press, vacuum filter) can only remove free water and an insignificant amount of intestinal water resulting in a high water content sludge [9], they are commonly used in medium and large scale wastewater treatment plants [27] as too in the case of our plant. High water content in sludge is a treatment disadvantage, as the incineration of such residues is consequently uneconomical.

The very high TOC value of $30.3 \%$ (303 g/ $/ \mathrm{kg} \mathrm{d.m.)} \mathrm{and} \mathrm{LOI} \mathrm{value} \mathrm{of} 74.3 \%$ (743 g/kg d.m.), which both measure the organic matter content of the sludge, are reasonable, since sewage sludge is rich in organic matter originating mainly from the treatment of household wastewaters (e.g. lavatories). From the utilization point of view, the high percentage of organic matter in the sludge measured as TOC is an important feature in deciding its destiny [28]. The high TOC value may also indicate that short-term improvement in soil properties from the application of sludge can be attributed to organic amendment and to the microbial production of humic substances. The $\mathrm{C} / \mathrm{N}$ ration in our sludge was 7.6. This is favourable, if the sludge is utilized as a fertilizer, since according Sogn et al. [4], a C/N ratio lower than about 25 usually means that the organic matter has a surplus of $\mathrm{N}$ relative to the $\mathrm{N}$ demand of the soil microbial community, which then can be mineralized to $\mathrm{NH}_{4}{ }^{+}$, a plant-available mineral form of $\mathrm{N}$.

If we disregard $\mathrm{N}$, the concentration of which was not available in the Finnish humus, the total concentrations of other nutrients ( $\mathrm{P}, \mathrm{Ca}, \mathrm{Na}, \mathrm{K}, \mathrm{Mg}$ and $\mathrm{Zn}$ ) in our sewage sludge were clearly higher than those in the Finnish humus. This supports the utilization of sludge, for instance as an earth construction agent or a fertilizer (after hygienic treatment) instead of disposal in landfill sites, since the utilization of industrial residue always saves valuable natural raw materials. One measure of the suitability of organic residue as a nutrient source for plant growth is the ratio of the content of $\mathrm{Ca}$ to $\mathrm{Mg}$. It is generally accepted that this ratio should be a minimum of 6:1 [29]. The sewage sludge investigated in this study had a $\mathrm{Ca} / \mathrm{Mg}$ ratio of $7: 1$, indicating that no adjustment by liming would be needed.

\section{Total and BCR extractable heavy metal concentrations in the sewage sludge}

The total and BCR extractable concentrations of heavy metals in the sewage sludge investigated in this study are presented in Table 2, which also presents the properties of sewage sludges collected from wastewater treatments plants in 15 European countries, 
including Finland [22-24]. Although many heavy metals in our sewage sludge were clearly lower than the maximum concentrations reported in the literature for other sewage sludges collected from different European countries, the concentration of $\mathrm{Hg}(1.4 \mathrm{mg} / \mathrm{kg} \mathrm{d.m}$.) in our sludge was slightly higher.

In Finland, the Fertilizer Product Act [30] and the Fertilizer Product Decree [31] regulates the utilization of sewage sludge as a fertilizer product. The Fertilizer Product Act [30] and Decree [31] imposes maximum limit values on eight heavy metals (As, Cd, Cr, $\mathrm{Cu}, \mathrm{Ni}, \mathrm{Zn}, \mathrm{Pb}$ and $\mathrm{Hg}$ ) in sewage sludge used as a fertilizer product, which are given in Table 2. In Finland, the maximum limit values for the heavy metals listed above are more stringent than the maximum limit values allowed in the European Union [32]. Except for $\mathrm{Hg}(1.4 \mathrm{mg} / \mathrm{kg}$ d.m.), the total concentrations of $\mathrm{As}, \mathrm{Cd}, \mathrm{Cr}, \mathrm{Cu}, \mathrm{Ni}, \mathrm{Zn}$ and $\mathrm{Pb}$ in our sewage sludge were lower that the Finnish maximum permissible trace element concentrations for sewage sludge used as a fertilizer product. Although the total concentration of $\mathrm{Hg}$ in our sludge was slightly higher than the maximum limit value for $\mathrm{Hg}$ permitted in sludge used as a fertilizer product in Finland, it was lower than the present maximum criteria value between 16 and $25 \mathrm{mg} / \mathrm{kg}$ d.m. for sludge according to $\mathrm{EU}$ Directive 86/278/EEC [32].

Table 2

The total heavy metal concentrations in sewage sludge investigated in this sludge, the corresponding maximum concentrations in other EU sludges [22-24], and the limit values for sludge used as a fertilizer product in Finland

$[30,31]$ as well as the extractable concentrations of heavy metals in our sewage sludge and the recovery values

\begin{tabular}{|c|c|c|c|c|c|c|c|}
\hline \multirow{2}{*}{ Metal } & \multicolumn{3}{|c|}{$\begin{array}{l}\text { Total concentration } \\
{[\mathrm{mg} / \mathrm{kg} \text { d.m.] }}\end{array}$} & \multicolumn{3}{|c|}{$\begin{array}{c}\text { Extractable concentration } \\
{[\mathrm{mg} / \mathrm{kg} \text { d.m. }]}\end{array}$} & \multirow{2}{*}{$\begin{array}{c}\text { Recovery } \\
{[\%]}\end{array}$} \\
\hline & $\begin{array}{l}\text { This } \\
\text { study }\end{array}$ & $\begin{array}{c}\text { EU sludge } \\
(\max )\end{array}$ & Limit value & BCR1 & BCR2 & BCR3 & \\
\hline $\mathrm{Al}$ & 2150 & 60000 & & 12.0 & 657 & 629 & 60.4 \\
\hline As & $<3.0$ & 56.1 & 25 & $<0.6$ & 1.3 & 1.6 & \\
\hline $\mathrm{Ba}$ & 330 & 580 & & 13.0 & 218 & 54 & 86.4 \\
\hline $\mathrm{Cd}$ & 0.5 & 5.1 & 1.5 & 0.1 & 0.2 & 0.2 & 100 \\
\hline $\mathrm{Co}$ & 3.2 & 16.7 & & 0.8 & 0.6 & 1.1 & 75.0 \\
\hline $\mathrm{Cr}$ & 29.0 & 1542 & 300 & $<0.4$ & 3.4 & 9.7 & \\
\hline $\mathrm{Cu}$ & 370 & 578 & 600 & 12.0 & 164 & 138 & 84.9 \\
\hline $\mathrm{Be}$ & $<1.0$ & & & $<0.2$ & $<0.2$ & $<0.3$ & \\
\hline $\mathrm{Fe}$ & 69000 & 149000 & & 3220 & 37100 & 17200 & 83.4 \\
\hline $\mathrm{Mn}$ & 310 & 960 & & 153 & 103 & 28 & 91.2 \\
\hline $\mathrm{Sb}$ & $<3.0$ & 53.6 & & $<0.6$ & $<0.6$ & $<0.8$ & \\
\hline Mo & 2.3 & 12.5 & & $<0.2$ & $<0.2$ & 1.6 & \\
\hline $\mathrm{Ni}$ & 14.0 & 310 & 100 & 4.3 & 3.2 & 2.5 & 71.4 \\
\hline $\mathrm{Zn}$ & 350 & 1200 & 1500 & 149 & 142 & 30 & 91.7 \\
\hline $\mathrm{Pb}$ & 10.0 & 430 & 100 & $<0.6$ & 3.4 & 4.9 & \\
\hline $\mathrm{S}$ & 7640 & & & 908 & 335 & 3220 & 58.4 \\
\hline $\mathrm{V}$ & 11.0 & 135 & & $<0.4$ & 4.7 & 2.8 & \\
\hline $\mathrm{Se}$ & $<3.0$ & & & $<0.6$ & $<0.6$ & 1.6 & \\
\hline $\mathrm{Ti}$ & 260 & 1071 & & $<0.6$ & 2.3 & 19.0 & \\
\hline $\mathrm{Hg}$ & 1.4 & 1.1 & 1.0 & $<0.1$ & $<0.1$ & $<0.1$ & \\
\hline
\end{tabular}

Although the $\mathrm{Hg}$ concentration of $1.4 \mathrm{mg} / \mathrm{kg}$ d.m. in our sewage sludge exceeded the $\mathrm{Hg}$ limit value of $1.0 \mathrm{mg} / \mathrm{kg} \mathrm{d}$.m. for fertilizer products, the sewage sludge may be utilized as a soil improver, a growing media or as a fertilizer product in landfill sites (e.g. surface structures) or in other closed industrial areas, because the above mentioned Finnish limit 
values are not applied at these sites. However, if the sewage sludge is to be utilized in these kinds of areas, an environmental permit may be needed.

The first extractable fraction of the BCR method is the exchangeable and acid-soluble fraction in which heavy metals are extracted with $\mathrm{CH}_{3} \mathrm{COOH}$ (abbreviation BCR1 in Table 2). This fraction gives an indication of the quantity of elements (metals) bound on surface of particles, as well as those that are released as acid-soluble salts such as carbonates. This fraction is very unstable and sensitive to environmental conditions [13] and is susceptible to acid rain [32]. Since the elements in this fraction are liable to change with environmental conditions, this phase is susceptible to change in $\mathrm{pH}$ and metals have the potential to be released by merely changing the ionic strength of the medium [11]. According to Golia et al. [33], acetic acid is found among the natural organic acids secreted by plants' roots, so the metals extracted by acetic acid may be similar to the fraction of metals available to plants. The highest extractable concentration in this fraction was observed for Fe (3220 mg/kg d.m.) followed by S (908 mg/kg d.m.), Mn (153 mg/kg d.m.) and $\mathrm{Zn}(149 \mathrm{mg} / \mathrm{kg}$ d.m.).

The second extractable fraction of the BCR method is the reducible fraction, in which heavy metals are extractable with a strong reducing agent of hydroxylamine hydrochloride $\left(\mathrm{NH}_{2} \mathrm{OH}-\mathrm{HCl}\right.$ ) in nitric acid medium (abbreviation BCR2 in Table 2). In the BCR extraction, this fraction is characterised as the fraction showing the content of heavy metals bound to manganese and iron oxides which could be released into the environment under reducing conditions [34]. The highest extractable concentration in this fraction was observed for Fe (37100 mg/kg d.m.) followed by Al (657 mg/kg d.m.), S (335 mg/kg d.m.), $\mathrm{Ba}(218 \mathrm{mg} / \mathrm{kg}$ d.m.), $\mathrm{Cu}(164 \mathrm{mg} / \mathrm{kg} \quad$ d.m. $), \quad \mathrm{Zn}(142 \mathrm{mg} / \mathrm{kg}$ d.m.) and $\mathrm{Mn}$ (103 mg/kg d.m.).

The third extractable fraction of the BCR method is the oxidizable fraction, in which the combination of $\mathrm{H}_{2} \mathrm{O}_{2}$ digestion and $\mathrm{CH}_{3} \mathrm{COONH}_{4}$ extraction is used (abbreviation BCR3 in Table 2). This fraction corresponds to metals that are organically bound or occur as oxidizable minerals, e.g. sulphides [18]. As metals bound to this fraction can be released under oxidising conditions, an oxidation process is usually applied to extract metals associated with the above-mentioned phase. Although, the heavy metals associated with the organic fraction are not considered to be very mobile or available [7], they may be released from the sludge matrix during decomposition processes [35]. The highest extractable concentration in this fraction was observed for Fe $(17200 \mathrm{mg} / \mathrm{kg} \mathrm{d.m}$.) followed by $\mathrm{S}$ (3220 mg/kg d.m.), Al (629 mg/kg d.m.), Cu (138 mg/kg d.m.), Ba (54 mg/kg d.m.), Zn (30 mg/kg d.m.), Mn (28 mg/kg d.m.) and Ti (19.0 mg/kg d.m.).

When the results of the total heavy metal concentrations and the sum of BCR-sequential extraction are compared (Table 2), it can be seen that the recovery values (solubility) of elements varied between 58.4 and $100 \%$. If we disregard elements whose concentrations are lower than the detection limits, the lowest recovery value of $58.4 \%$ was observed for $\mathrm{S}$ and the highest value of $100 \%$ for $\mathrm{Cd}$. From the environmental point of view, the relatively low recovery value of sulphur indicates that this element is poorly released from the sludge matrix, whereas the cadmium is easily released. Although the recovery values were high for many elements. According to Lorentzen and Kingston [36], the BCR sequential extraction procedure illustrates the worst-case environmental scenarios, in which the components of the sample become soluble and mobile.

If we compare the BCR extraction results of this study to our previous publication [15], in which the wastewater treatment sludge was originated from the semi-chemical pulp 
mill (NSSC), the leaching behaviour and the release potential of sulphur (S) was significantly lower in this study, because in the NSSC pulp mill sludge it was ca. $96.1 \%$. Furthermore, the highest release potential from the NSSC pulp mill sludge was observed Al with the recovery value of $94 \%$. This indicates that the heavy metals in different kinds of sludges may be bound to sample matrix with different strengths.

\section{Accuracy and quality control of the BCR extraction procedure}

The accuracy and quality control of the three-step BCR extraction procedure used in this study is assessed in our previous publication [37]. The accuracy and quality control were carried out using a certified reference material BCR-701 (lake sediment). Our results for the reference material suggested that the extraction procedure and instrumental analysis of the extraction used in this study were accurate.

\section{Conclusions}

The total concentrations of nutrients ( $\mathrm{P}, \mathrm{Ca}, \mathrm{Na}, \mathrm{K}, \mathrm{Mg}$ and $\mathrm{Zn}$ ) in our sewage sludge were clearly higher than those in the Finnish humus. This supports the utilization of sludge as a fertilizer. However, due to the elevated total concentration of $\mathrm{Hg}(1.4 \mathrm{mg} / \mathrm{kg} \mathrm{d.m}$.), which was slightly higher than the maximum limit value of $1.0 \mathrm{mg} / \mathrm{kg} \mathrm{d.m}$. for $\mathrm{Hg}$ permitted in fertilizer products in Finland, this sludge fraction is not permitted to be used as a fertilizer in agriculture. Therefore, other option for this sludge fraction has to be found.

Although the $\mathrm{Hg}$ concentration of $1.4 \mathrm{mg} / \mathrm{kg} \mathrm{d} . \mathrm{m}$. in the sewage sludge exceeded the $\mathrm{Hg}$ limit value of $1.0 \mathrm{mg} / \mathrm{kg} \mathrm{d.m}$. for fertilizer products, the sewage sludge may be utilized as a soil improver, a growing media or as a fertilizer product in landfill sites (e.g. surface structures) or in other closed industrial areas, because the above mentioned Finnish limit values are not applied at these sites. However, if the sewage sludge is to be utilized in these kinds of areas, an environmental permit may be needed. Then the knowledge of the extractability of heavy metals in sludge is needed.

\section{Acknowledgements}

The authors wish to thank the technical staff of Ahma Ympäristö Oy, who kindly conducted all the chemical analyses. Special thanks also to Sami Saukko at the Center of Microscopy and Nanotechnology, University of Oulu, Finland, for the XRD data.

\section{References}

[1] Harrison EZ, McBride MB, Bouldin DR. Land application of sewage sludges: an appraisal of the US regulations. Int J Environ Pollut. 1999;11:1-36. DOI: 10.1504/IJEP.1999.002247.

[2] Fytili D, Zabaniotou A. Utilization of sewage sludge in EU application of old and new methods - A review. Renew Sust Energy Rev. 2008;12:116-140. DOI: 10.1016/j.rser.2006.05.014.

[3] Brod E, Haraldsen TK, Breland TA. Fertilization effects of organic waste resources and bottom wood ash: results from a pot experiment. Agric Food Sci. 2012;21:332-347. DOI: 10.23986/afsci.5159.

[4] Sogn TA, Dragicevic I, Linjordet R, Krogstad T, Eijsink VGH, Eich-Greatorex S. Recycling of biogas digestates in plant production: NPK fertilizer value and risk of leaching. Int J Recycl Org Waste Agricult. 2018;7:49-58. DOI: 10.1007/s40093-017-0188-0.

[5] Healy MG, Fenton O, Forrestal PJ, Danaher M, Brennan RB, Morrison L. Metal concentrations in lime stabilised, thermally dried and anaerobically digested sewage sludges. Waste Manage. 2016;48:404-408. DOI: 10.1016/j.wasman.2015.11.028. 
[6] Mattana S, Petrovičová B, Landi L, Gelsomino A, Cortés P, Ortiz O, et al. Sewage sludge processing determines its impact on soil microbial community structure and function. Appl Soil Ecol. 2014;75:150-161. DOI: 10.1016/j.apsoil.2013.11.007.

[7] Hei L, Jin P, Zhu X, Ye W, Yang Y. Characteristics of speciation of heavy metals in municipal sewage sludge of Guangzhou as fertilizer. Procedia Environ Sci. 2016;31:232-240. DOI: 10.1016/j.proenv.2016.02.031.

[8] Pérez Cid B, Alborés FA, Gómez EF, López FE. Metal fractionation in olive oil and urban sewage sludges using the three-stage BCR sequential extraction method and microwave single extractions. Analyst. 2001;126(8):1304-1311. DOI: 10.1039/B102768A.

[9] Tuan PA, Sillanpää M. Fractionation of macro and trace metals due to off-time interrupted electrodewatering. Drying Technol. 2010;28:762-772. DOI: 10.1080/07373937.2010.482693.

[10] Santoro A, Held A, Linsinger TPJ, Perez A, Ricci A. Comparison of total and aqua regia extractability of heavy metals in sewage sludge: The case study of a certified reference material. Trends Analyt Chem. 2017;89:34-40. DOI: 10.1016/j.trac.2017.01.010.

[11] Kazi TG, Jamali MK, Kazi GH, Arain MB, Afridi HI, Siddiqui A. Evaluating the mobility of toxic metals in untreated industrial wastewater sludge using a BCR sequential extraction procedure and a leaching test. Anal Bioanal Chem. 2005;383:297-304. DOI: 10.1007/s00216-005-0004-y.

[12] EPA. Industrial waste resources guidelines-sampling and analysis of waters, wastewaters, soils and wastes. 2009. http://www.epa.vic.gov.au.

[13] Stylianou MA, Kollia D, Haralambous KJ, Inglezakis VJ, Moustakas KG, Loizidou MD. Effect of acid treatment on the removal of heavy metals from sewage sludge. Desalination. 2007;215:73-81. DOI: 10.1016/j.desal.2006.11.015.

[14] Khaliq SJA, Al-Busaidi A, Ahmed M, Al-Wardy M, Agrama H, Choudri BS. The effect of municipal sewage sludge on the quality of soil and crops. Int J Recycl Org Waste Agricult. 2017;6:289-299. DOI: 10.1007/s40093-017-0176-4.

[15] Pöykiö R, Manskinen K, Oksanen J, Nurmesniemi H, Dahl O. Chemical characterisation of biosludge from a wastewater treatment plant in a neutral sulphite semi-chemical pulp mill by single and sequential extraction of heavy metals and micro-/macronutrients - a case study. Chem Pap. 2014;68:1546-1554. DOI: 10.2478/s11696-014-0606-y.

[16] Yafa Y, Farmer JG. A comparative study of acid-extractable and total digestion methods for the determination of inorganic elements in peat material by inductively coupled plasma-optical emission spectrometry. Anal Chim Acta. 2006;557:296-303. DOI: 10.1016/j.aca.2005.10.043.

[17] Kaakinen J, Kuokkanen T, Pesonen J, Välimäki I. Comparison of different standard methods to evaluate the total concentrations of heavy metals in waste rock. Soil Sediment Contam. 2014;23:437-451. DOI: 10.1080/15320383.2014.831808.

[18] Filgueiras A, Lavilla I, Bendicho C. Chemical sequential extraction for metal partitioning in environmental solid samples. J Environ Monit. 2002;4:823-857. DOI: 10.1039/B207574C.

[19] Karczmarek A, Studziński W. Effect of sludge sample drying before the determination of mobility of metals by sequential extraction method. World Sci News. 2017;73(1):24-33. http://www.worldscientificnews.com/wp-content/uploads/2017/05/WSN-731-2017-24-33-1.pdf.

[20] Dąbrowska L. Speciation of heavy metals in non-volatile solids of sewage sludge. Desalin Water Treat. 2014;52:3761-3766. DOI: 10.1080/19443994.2014.884750.

[21] Wang J, Xue Q. Study on microscopic characteristics and analysis methods of municipal sludge. EJGE. 2010;15:441-448. http://www.ejge.com/.

[22] Tavazzi S, Locoro G, Comero S, Sobiecka E, Loos R, Gans O, et al. Occurrence and levels of selected compounds in European sewage sludge samples. Results of a Pan-European Screening Exercise (FATE SEES). JRC Scientific and Policy Reports. European Commission. Joint Research Centre. Institute for Environment and Sustainability. Luxembourg: European Union; 2012. DOI: 10.2788/67153. http://ies.jrc.ec.europa.eu/.

[23] Alakangas E, Hurskainen M, Laatikainen-Luntama J, Korhonen J. Properties of fuels in Finland, VTT Technical Research Centre of Finland Ltd., VTT Finland, VTT Technical Report 272, Finland; 2016. http://vtt.fi.

[24] Nyyssonen V, Wenying X, Mondal PK, Oskenbayeva A, Neupane RK. Study on economic sustainability of sewage sludge treatment plants in China and Finland. Int J Adv Res. 2017;5:1763-1772. DOI: 10.21474/IJAR01/3689.

[25] El-Nahhal IY, Al-Najar H, El-Nahhal Y. Physiochemical properties of sewage sludge from Gaza. IJG. 2014;5:586-594. DOI: 10.4236/ijg.2014.56053.

[26] Yang GCC, Chen MC, Yeh CF. Dewatering of a biological industrial sludge by electrokinetics-assisted filter press. Sep Purif Technol. 2011;79:177-182. DOI: 10.1016/j.seppur.2011.02.012. 
[27] Pham AT, Sillanpää M, Virkutyte J. Sludge dewatering by sand-drying bed coupled with electro-dewatering at various potentials. Int J Min Reclam Environ. 2010;24:151-162. DOI: 10.1080/17480930903132620.

[28] Zufiaurre R, Olivar A, Chamorro P, Nerin C, Callizo A. Speciation of metals in sewage sludge for agricultural uses. Analyst. 1998;123:255-259. DOI: 10.1039/A7051681.

[29] Rato Nunes J, Cabral F, López-Piňeiro A. Short-term effects on soil properties and wheat production from secondary paper sludge application on two Mediterranean agricultural soils. Bioresour Technol. 2008;99:4935-4942. DOI: 10.1016/j.biortech.2007.09.016.

[30] The Fertilizer Product Act 539/2006. Lannoitevalmistelaki (539/2006) (in Finnish). 2006. https://finlex.fi.

[31] The Fertilizer Product Decree 24/11 (Finnish Ministry of Agriculture and Forestry). Maa- ja metsätalousministeriön asetus lannoitevalmisteista. Asetus nro 24/11 (in Finnish). 2011. https://finlex.fi.

[32] Mattsson A, Finnson A, I'Ons D. Heavy metal content of Swedish municipal wastewater sludge - status and goals. Water Sci Technol. 2017;76:869-876. DOI: 10.2166/wst.2017.277.

[33] Golia EE, Tsiropoulos NG, Dimirkou A, Mitsios I. Distribution of heavy metals of agricultural soils of central Greece using the modified BCR sequential extraction method. Int J Environ Anal Chem. 2007;87:1053-1063. DOI: 10.1080/03067310701451012.

[34] Gwebu S, Navengwa NT, Klink MJ, Mtunzi FM, Modise SJ, Pakade VE. Quantification of Cd, $\mathrm{Cu}, \mathrm{Pb}$ and $\mathrm{Zn}$ from sewage sludge by modified-BCR and ultrasound assisted-modified BCR sequential extraction methods. Afr J Pure Appl Chem. 2017;11:9-18. DOI: 10.5897/AJPAC2016.0712.

[35] Łukowski A. Fractionation of heavy metals $(\mathrm{Pb}, \mathrm{Cr}$ and $\mathrm{Cd})$ in municipal sewage sludges from Podlasie province. J Ecol Eng. 2017;18:132-138. DOI: 10.12911/22998993/66244.

[36] Lorentzen EM, Kingston HMS. Comparison of microwave-assisted and conventional leaching using EPA method 3050B. Anal Chem. 1996;68:4316-4320. DOI: 10.1021/ac9605531.

[37] Pöykiö R, Mäkelä M, Watkins G, Nurmesniemi H, Dahl O. Heavy metals in bottom ash and fly ash fractions from industrial-scale BFB-boiler for environmental risks assessment. T Nonfer Met Soc. 2016;26:256-254. DOI: $10.1016 / \mathrm{S} 1003-6326(16) 64112-2$. 